\title{
Impossibilidade de mapeamentos bijetivos entre saberes matemáticos indígenas e eurocêntricos ${ }^{1}$
}

\author{
Kécio Gonçalves Leite ${ }^{2}$ iD \\ Universidade Federal de Rondônia (UNIR), Departamento de Educação Intercultural, Ji-Paraná, \\ Rondônia, Brasil \\ Quesler Fagundes Camargos 3 \\ Universidade Federal de Rondônia (UNIR), Departamento de Educação Intercultural, Ji-Paraná, \\ Rondônia, Brasil
}

\begin{abstract}
Resumo
Este artigo tem por objetivo abordar a problemática da tradução de saberes matemáticos em contextos da educação escolar indígena, a partir de três aspectos: (i) diferentes línguas se baseiam em sistemas de referência distintos, (ii) as lógicas de distintos saberes matemáticos não são equivalentes e (iii) há uma impossibilidade de mapeamentos bijetivos entre conjuntos de saberes matemáticos indígenas e eurocêntricos. Nesse sentido, problematiza-se a ideia de tradução isomórfica associada ao bilinguismo prescrito como característica da educação escolar indígena no Brasil. O tema é explorado teoricamente e ilustrado com a análise de produções textuais de estudantes indígenas de um curso de licenciatura intercultural na Amazônia. Como resultado, mostra-se que a ideia de tradução total de saberes matemáticos eurocêntricos entre língua portuguesa e línguas indígenas, inerente a uma concepção colonialista de educação escolar para povos indígenas, precisa ser superada, com vistas à decolonialidade da educação escolar indígena.
\end{abstract}

Palavras-chave: Etnomatemática; Tradução; Indígena; Decolonialidade.

Submetido em: 26/06/2021 Aceito em: 18/08/2021 Publicado em: 03/09/2021

${ }^{1}$ Agradecemos ao Prof. Dr. Selmo Azevedo Apontes pela leitura deste artigo e por sugerir algumas mudanças que certamente contribuíram com o presente texto. Possíveis erros que aqui permanecem são de nossa inteira responsabilidade. 2 Doutor em Educação em Ciências e Matemática pela UFMT. Professor do Programa de Pós-Graduação em Educação Matemática da Universidade Federal de Rondônia. Endereço para correspondência: Rua Rio Amazonas, 351, Jardim dos Migrantes, 76900-730, Ji-Paraná, Rondônia, Brasil. E-mail: kecioleite@ unir.br.

3 Doutor em Estudos Linguísticos pela UFMG. Professor do Programa de Pós-Graduação em Letras da Universidade Federal de Rondônia. Endereço para correspondência: Rua Rio Amazonas, 351, Jardim dos Migrantes, 76900-730, JiParaná, Rondônia, Brasil. E-mail: queslerc@unir.br. 


\title{
Impossibility of bijective mapping between indigenous and Eurocentric mathematical knowledge
}

\begin{abstract}
This article aims to discuss the problem of translating mathematical knowledge in contexts of indigenous school education, from three aspects: (i) different languages are based on different reference systems, (ii) the logics of different mathematical knowledge are not equivalent and (iii) there is an impossibility of bijective mappings between Indigenous and Eurocentric mathematical knowledge. In this sense, the conception of isomorphic translation associated with the prescribed bilingualism as a characteristic of indigenous school education in Brazil is problematized. This theme is explored theoretically and illustrated with the analysis of textual productions of indigenous students from an intercultural indigenous licentiate-degree course in the Amazon. As a result, it is shown that the idea of a total translation of Eurocentric mathematical knowledge between Portuguese and indigenous languages, inherent to a colonialist conception of school education for indigenous peoples, needs to be overcome, in order to promote the decoloniality of indigenous school education.
\end{abstract}

Keywords: Ethnomathematics; Translation; Indigenous; Decoloniality.

\section{Imposibilidad del mapeo bijetivo entre conocimientos matemáticos indígenas y eurocéntricos}

\section{Resumen}

Este trabajo tiene como objetivo abordar el problema de la traducción de conocimientos matemáticos en contextos de educación escolar indígena, desde tres aspectos: (i) los diferentes lenguajes se basan en diferentes sistemas de referencia, (ii) las lógicas de los diferentes conocimientos matemáticos no son equivalentes, y (iii) hay una imposibilidad de mapeos biyectivos entre conjuntos de conocimientos matemáticos indígenas y eurocéntricos. En este sentido, se problematiza la idea de traducción isomórfica asociada al bilingüismo prescrito como característica de la educación escolar indígena en Brasil. El tema es explorado teóricamente e ilustrado con el análisis de producciones textuales de estudiantes indígenas de un curso de formación docente intercultural en la Amazonía. Como resultado, se muestra que la idea de una traducción total del conocimiento matemático eurocéntrico entre el portugués y las lenguas indígenas, inherente a una concepción colonialista de la educación escolar para los pueblos indígenas, debe ser superada, con miras a la descolonialidad de la educación escolar indígena.

Palabras clave: Etnomatemática; Traducción; Indígena; Decolonialidad.

\section{Introdução}

A demonstração de que existem distintos saberes matemáticos originados e situados em diferentes contextos socioculturais é uma das contribuições de pesquisas em etnomatemática desenvolvidas a partir do final do século XX. Como um de seus desdobramentos, essa contribuição possibilitou um questionamento do caráter universal atribuído à matemática presente em currículos escolares, abrindo espaço para o pensamento e para a ação na direção da valorização da multiplicidade de saberes matemáticos e de suas respectivas matrizes epistemológicas (D’AMBROSIO, 1990, 2001; POWELL; FRANKENSTEIN, 1997; KNIJNIK, 1998; FANTINATO; FREITAS, 2018). 
A efetiva desconstrução de uma concepção moderna de matemática, que lhe atribui características de universalidade, com efeitos para a reorientação oficial de políticas públicas de educação e de práticas escolares, passa necessariamente pela superação da condição de subalternidade em que se encontram as formas de ser e de saber de povos que historicamente foram submetidos à dominação colonial europeia. Nesse sentido, passa pelo enfrentamento à concepção colonialista eurocêntrica de que a humanidade é composta de povos inferiores e superiores, irracionais e racionais, primitivos e civilizados, tradicionais e modernos (QUIJANO, 2010).

Por concepção colonialista eurocêntrica, compreende-se uma perspectiva de conhecimento e de racionalidade, originada na Europa Ocidental em meados do século XVII, que, embora não abarque todos os modos de conhecer de todos os europeus e em todas as épocas, tornou-se "mundialmente hegemônica, colonizando e sobrepondo-se a todas as demais, prévias ou diferentes, e a seus respectivos saberes concretos, tanto na Europa como no resto do mundo" (QUIJANO, 2005, p. 126). Como efeito do caráter hegemônico da colonialidade eurocêntrica, reproduzida ao longo do tempo nas diferentes regiões sob domínio do capitalismo colonial moderno, o eurocentrismo deixou de ser uma perspectiva cognitiva exclusiva dos europeus e passou a ser reproduzida também pelo conjunto dos educados sob a sua hegemonia (QUIJANO, 2010).

Embora tenha uma dimensão etnocêntrica, o eurocentrismo não se restringe a essa dimensão, nem é uma questão de geografia, mas sim de epistemologia. Assim, como concepção de conhecimento originada na Europa, "poderia ser encontrado e reproduzido nas colônias e ex-colônias, assim como em locais que não foram diretamente colonizados" (MIGNOLO, 2017, p. 12). Dessa forma, como estrutura epistêmica da modernidade colonial, o eurocentrismo desconsidera sistematicamente a multiplicidade de racionalidades e epistemologias existentes no mundo ou, quando muito, as concebe de forma hierárquica, com a Europa no topo de uma escala linear do desenvolvimento humano.

Uma das consequências da perspectiva hegemônica do eurocentrismo é o modo como certos saberes podem ser reconhecidos ou não como sendo matemáticos, de modo que "o tratamento padrão da história da matemática não europeia é produto de um viés historiográfico (consciente ou não) na seleção e interpretação de fatos que, como consequência, resulta em ignorar, desvalorizar ou distorcer as contribuições que surgem fora das tradições matemáticas europeias" (JOSEPH, 1987, p. 14). Essa distorção reflete-se nos currículos escolares, reduzindo e limitando as possibilidades de se promover pela educação escolar o conhecimento dos diferentes saberes produzidos pela humanidade, mas situados fora do complexo cultural eurocêntrico (SWARTZ, 1992; WILLINSKY, 1998).

Especificamente para os povos indígenas no Brasil, o processo de colonização iniciado pelos europeus e conduzido internamente mesmo após o período histórico do colonialismo, além de 
promover genocídio, representa também o epistemicídeo (SANTOS, 2007a), por negar o caráter racional a todas as formas de conhecimento que não se pautam pelos princípios epistemológicos da racionalidade científica característica do pensamento moderno (SANTOS, 2010).

De certo modo, a atual fase histórica em que se encontra a educação escolar indígena incorpora entre seus princípios a superação de paradigmas do pensamento moderno europeu, preconizando o reconhecimento, a valorização e a promoção dos saberes próprios de cada povo, suas línguas, identidades, histórias e culturas, garantindo assim um caráter específico e diferenciado à escola em contextos indígenas.

Entre os recursos para se fazer essa educação escolar específica e diferenciada em contextos indígenas encontra-se o bilinguismo, com vistas a possibilitar a estudantes de cada povo que possam estudar em suas próprias línguas maternas, estando esse direito garantido pela Constituição Federal de 1988 e legislação infraconstitucional. Todavia, mesmo em escolas e comunidades em que a língua dominante é indígena, é comum se observar o uso do português para a comunicação de ideias e conceitos da matemática escolar. D’Angelis ${ }^{4}$ (2001 apud NOBRE, 2012) aponta três tipos de bilinguismo: bilinguismo de transição, bilinguismo de manutenção ou de resistência e bilinguismo de imersão. Em cada uma dessas possibilidades de bilinguismo, é possível verificar uma aproximação ou um distanciamento de aspectos da colonialidade na educação escolar indígena, possibilitando problematizar o bilinguismo no caso do ensino de matemática em escolas indígenas. Surge, nesse contexto, o interesse pelo problema da tradução como tema de pesquisa em etnomatemática.

A tradução tem sido tema de interesse de pesquisadores em etnomatemática em distintos contextos. Monteiro (2016), em pesquisa com professores indígenas dos povos Xerente e Karajá, investigou processos de tradução e de criação de novos termos em línguas indígenas como tentativas de transferência de significados matemáticos da língua portuguesa para as línguas indígenas, chegando à conclusão de que os processos de tradução e de criação de novos termos em língua indígena não garantem a transferência de significados matemáticos entre as línguas. Eduardo Sebastiani, em entrevista concedida a Miarka (2011), menciona o desafio de se fazer pesquisa etnográfica em etnomatemática com povos indígenas, apontando para casos de impossibilidade de tradução. Por sua vez, Gelsa Knijnik, também em entrevista a Miarka (2011), menciona a tradução como temática de interesse em suas pesquisas em etnomatemática. Millroy (1992), em sua conhecida crítica, menciona a impossibilidade de se descrever distintos tipos de matemática em diferentes culturas sem se tomar como referência a própria matemática do pesquisador. Rosa e Orey (2017)

${ }^{4}$ D’ANGELIS, W. R. Relatório Curso de Formação de Educadores Kaingang. Aldeia de Votouro, RS: CGAEI/MEC, 2001. Mimeografado. 
apresentam a etnomodelagem como possibilidade de tradução de práticas matemáticas desenvolvidas por grupos socioculturais específicos.

Diante destas considerações iniciais, o presente artigo tem por objetivo abordar a problemática da tradução de saberes matemáticos em contextos da educação escolar indígena, a partir de três aspectos, a saber: (i) diferentes línguas se baseiam em sistemas de referência distintos; (ii) as lógicas de distintos saberes matemáticos não são equivalentes; e, por fim, (iii) há uma impossibilidade de mapeamentos bijetivos entre conjuntos de saberes matemáticos indígenas e eurocêntricos.

\section{Diferentes línguas se baseiam em sistemas de referência distintos}

A possibilidade ou impossibilidade de mapeamentos bijetivos em traduções entre línguas distintas derivam diretamente de concepções que se assumam a respeito da linguagem. Há no pensamento ocidental pelo menos duas perspectivas opostas. Por um lado, podem-se citar como exemplos as concepções de linguagem originadas por Descartes (1596 - 1650), Hobbes (1588 - 1679) e Leibniz (1646 - 1716), marcadas pela busca da certeza e da objetividade, assumindo a matemática como modelo epistemológico subjacente. Por outro lado, há concepções que consideram as línguas não apenas como formas de comunicação da realidade, mas também como constitutivas da própria realidade, como assumiram Whorf $(1897$ - 1941) e Saussure $(1857$ - 1913).

Para Descartes, para bem representar a imaginação e os pensamentos seria necessário designálos "por alguns signos, os mais breves possíveis, e que, por esse meio, tomasse de empréstimo o melhor da análise geométrica e da álgebra" (DESCARTES, 2003, p. 28). Essa concepção cartesiana baseia-se numa dicotomia entre pensamento e linguagem, pressupondo uma natureza não discursiva do pensamento. Nesse caso, a existência de um sistema de signos se dá meramente pela necessidade de comunicação do pensamento, não sendo determinante sobre ele. A precisão de um bom sistema de signos nesse caso seria obtida se estivesse baseada em modelo matemático, a exemplo da geometria e da álgebra, a fim de "dispor juntas diversas palavras, e de compor com elas um discurso pelo qual façam entender seus pensamentos" (DESCARTES, 2008, p. 97).

Para Hobbes, a compreensão da realidade dependeria de uma associação de cada elemento do mundo material a um nome. Os nomes constituiriam assim o elo entre a sensação e o pensamento racional, de modo que a compreensão da realidade dependeria diretamente da definição de cada palavra usada para representar as coisas e não das coisas sobre as quais se discursa, uma vez que, para Hobbes, o verdadeiro e o falso seriam atributos da linguagem e não das coisas. Essa concepção de linguagem também assume a matemática como modelo de precisão e objetividade. Assim, Hobbes ilustrou sua concepção de linguagem com uma analogia à geometria, na qual "os homens começam 
por estabelecer as significações de suas palavras, e a esse estabelecimento de significações chamam definições, e colocam-na no início do seu cálculo" (HOBBES, 1996, p. 46).

Para Leibniz, a linguagem seria fundamental para o pensamento, porque as operações mentais ou os raciocínios não se dariam diretamente sobre os objetos e coisas a respeito dos quais se pensa, mas sim sobre os símbolos e signos que representam tais objetos. No entanto, Leibniz concebeu a possibilidade de uma linguagem universal, tomando a matemática como modelo epistemológico, que fosse capaz de representar a estrutura do raciocínio humano, servindo como instrumento de formalização do pensamento. Por conseguinte, Leibniz afirma que

Todo raciocínio humano se consuma por meio de certos sinais e caracteres. Pois não apenas as próprias coisas, mas também as idéias das coisas, não podem nem devem ser sempre observadas distintamente pelo ânimo, e, assim, para resumir, são empregados sinais ao invés delas. Pois ... se, durante um cálculo, um aritmético pensasse continuamente nos valores e na multiplicidade de unidades de todas as notas ou cifras que escreve, nunca solucionaria cálculos extensos, do mesmo modo que se quisesse utilizar a mesma quantidade de pedras (LEIBNIZ ${ }^{5}, 1988$ apud MOREIRA, 2005, p. 69-70).

Nesta perspectiva exemplificada pelas concepções de linguagem de Descartes, Hobbes e Leibniz, embora as línguas sejam importantes, quer seja para a comunicação do pensamento, quer seja para o entendimento da realidade, haveria sempre a possibilidade de uma representação objetiva e universal da realidade, bastando para isso nomear adequadamente as coisas ou operar adequadamente os sistemas de signos.

Associada a esta perspectiva de linguagem está a ideia de tradução total, segundo a qual a matemática escolar seria universal, sendo assim possível de ser traduzida em todas as línguas, sem alteração nos sentidos e significados de seus termos. Dessa forma, seria adequado e suficiente que o ensino de matemática escolar em contextos indígenas partisse de exemplos contextualizados nas culturas locais, para então se atingir a compreensão do que nela seria universal.

Diferentemente desta linha de pensamento marcada pela objetividade e pela busca da certeza, há concepções que consideram as línguas não apenas como formas de comunicação da realidade, mas também como constitutivas da própria realidade. A este respeito, não se pode deixar de destacar o que afirma Feyerabend (2011, p. 215):

Tenho grande simpatia pela ideia, clara e elegantemente formulada por Whorf (e antecipada por Bacon), de que as línguas e os padrões de reação que envolvem não são meros instrumentos para descrever eventos (fatos, estados de coisas), mas que

\footnotetext{
${ }^{5}$ LEIBNIZ, G. W. Opuscules et fragments inédits: Extraits des manuscrits de la Bibliothèque Royale de Hanovre. Hildesheim: Georg Olms, 1988.
} 
são também modeladores de eventos (fatos, estados de coisas), que sua "gramática" encerra uma cosmologia, uma visão abrangente do mundo, da sociedade e da situação do ser humano, que influencia o pensamento, o comportamento e a percepção.

Para Whorf ${ }^{6}$ (1956 apud FEYERABEND, 2011), o sistema linguístico de fundo das línguas, que para o autor corresponde a sua gramática, não é um simples sistema reprodutor com a finalidade de exprimir ideias. Na verdade, este sistema é um modelador de ideias, que se constitui em um programa e um guia para a atividade mental. Desta maneira, a estrutura da língua influencia os processos de pensamento do indivíduo. Nesta perspectiva teórica, a representação que o indivíduo faz da realidade é determinada por sua língua materna. Assim, "usuários de gramáticas marcadamente diferentes são levados por suas gramáticas a diferentes tipos de observações” (WHORF, 1956 apud FEYERABEND, 2011, p. 215).

Considerando esta perspectiva de Whorf (1956), que passou a ser denominada como “Hipótese da Relatividade Linguística”, Feyerabend (2011, p. 247-248) afirma que

Apenas poucos filósofos estão preparados para conceder que as estruturas básicas subjacentes a algum idioma recém-descoberto podem diferir radicalmente das estruturas básicas dos sistemas mais familiares da lógica formal, e absolutamente ninguém está preparado para admitir que isso poderia ser verdadeiro também para a ciência. Na maioria das vezes, a "lógica" [...] de uma linguagem ou de uma teoria particular é imediatamente identificada com os aspectos de um particular sistema lógico, sem que se considere a necessidade de uma investigação concernente à adequação de tal identificação.

Diante dessas duas concepções a respeito da linguagem humana, que contrasta as perspectivas de Descartes, Hobbes e Leibniz, por um lado, e Whorf, por outro, é imprescindível que se compreenda o que denominamos como língua. Para isso, decidimos tomar como referência o "Curso de Linguística Geral", de Ferdinand de Saussure, que remonta ao início do século XX. Seu legado é indubitável, tendo em vista seu papel fundador da Linguística como ciência autônoma, ao constituir bases científicas e epistemológicas para a Linguística, definindo subáreas e delimitando sua interface com outras ciências.

Nesta perspectiva, a Linguística é abarcada por uma ciência mais ampla, a Semiologia, que, conforme Saussure (2006, p. 24), tem por objetivo estudar a vida "dos signos no seio da vida social". Além disso, para Saussure (2006, p. 17), a língua é "um produto social da faculdade de linguagem e

${ }^{6}$ WHORF, B. Language, Thought and Reality: selected writings. Cambridge: Technology Press of Massachusetts Institute of Technology, 1956. 
um conjunto de convenções necessárias, adotadas pelo corpo social para permitir o exercício dessa faculdade nos indivíduos".

Acerca ainda deste caráter indissociável entre língua e sociedade, "nenhuma sociedade conhece nem conheceu jamais a língua de outro modo que não fosse como um produto herdado de gerações anteriores e que cumpre receber como tal" (SAUSSURE, 2006, p. 86). Além disso, os conjuntos de convenções adotadas pelo grupo social atuam em função do tempo e do peso da coletividade de forma inseparável, razão pela qual Saussure (2006, p. 86) afirma que "um dado estado de língua é sempre o produto de fatores históricos e são esses fatores que explicam porque o signo é imutável, vale dizer, porque resiste a toda substituição". Dessa maneira, para Saussure (2006, p. 88), "a todo instante, a solidariedade com o passado põe em xeque a liberdade de escolher. Dizemos homem e cachorro porque antes de nós se disse homem e cachorro".

No entanto, de forma paradoxal, ao mesmo tempo em que o tempo assegura a continuidade do signo, preservando a relação entre o significado e o significante, também permite sua mutabilidade, de forma que haja um deslocamento dessa relação. Funda-se aí o caráter arbitrário do signo. Por esta razão, "o fato social pode, por si só, criar um sistema lingüístico. A coletividade é necessária para estabelecer os valores cuja única razão de ser está no uso e no consenso [...]" (SAUSSURE, 2006, p. 131). Esta mutabilidade linguística, por conseguinte, implica necessariamente em diversidade de línguas que foi notada sabidamente por Saussure (2006, p. 221), ao afirmar que

o que primeiro surpreende no estudo das línguas é sua diversidade, as diferenças lingüísticas que se apresentam quando se passa de um país a outro [...]. Conquanto as divergências no tempo escapem ao observador, as divergências no espaço saltam imediatamente aos olhos.

Ora, se de fato a língua é um produto social da faculdade de linguagem e um conjunto de convenções definidas pelo grupo social, como afirma Saussure (2006), tão maiores devem ser as diferenças entre as línguas quanto maiores forem os demais fatores que a determinam. Assim, a língua deve ter um forte vínculo com as experiências do grupo social a qual pertence. Cada um destes fatos particulares certamente é relevante para fornecer a cada língua características que lhe são importantes no que diz respeito à relação indissociável entre o significante (imagem acústica) e o significado (conceito).

Ao comparar línguas não geneticamente relacionadas, por exemplo, é muito pouco provável identificar signos que se aproximam quanto ao seu significante, talvez exceto em contexto de empréstimo linguístico. No entanto, quanto ao significado, esta tarefa parece ser mais passível. De outra forma, é pouco provável que não encontremos na maioria das línguas do mundo signos cujos 
significados sejam correlatos, por exemplo, a "homem", "mulher", "pai" e "mãe”, uma vez que tais signos em português parecem denotar seres - e relações entre seres - comuns a toda sociedade humana. No entanto, o fato de em toda sociedade humana haver uma progenitora não significa necessariamente que todos os povos convencionalizaram tal relação da mesma maneira. Em português, "mãe", de modo geral, não é só aquela que tem ou teve filhos, mas também aquela que cria ou criou um indivíduo que não gerou e com quem estabeleceu laços maternais e/ou está ligada por vínculos jurídicos. O significado em português certamente é o resultado, utilizando Saussure (2006), de convenções adotadas em função do tempo e do peso da coletividade e, tendo em vista o fator arbitrário do signo, pode ser que sofra modificações no futuro. Em outros povos, é provável que o signo cujo significado compreenda aquela que é progenitora exclua ou inclua outros significados que não existem em português.

De modo paralelo, há signos cujo significado definitivamente não se espera encontrar em todas as línguas do mundo. As palavras para "neve" e "furacão", por exemplo, possivelmente não devem existir em línguas indígenas da Amazônia brasileira, pelo simples fato de se referir a fenômenos meteorológicos que não ocorrem nessa região geográfica. No entanto, nada impede que, devido a algum fator de natureza extralinguística, o grupo social modifique seu conjunto de convenções e incorpore em seu vocabulário signos que denotem estes sentidos - seja por meio de empréstimo ou neologismo, por exemplo.

Outro interessante exemplo para ilustrar a importância das convenções adotadas por grupos sociais encontra-se nos sistemas de cores disponíveis nas línguas naturais. A princípio, pode-se afirmar que todos os seres humanos, exceto aqueles que apresentam algum grau de cegueira, incluindo-se nestes grupos os que apresentam qualquer um dos tipos de daltonismo, por exemplo, são capazes de enxergar o mesmo espectro de cores. No entanto, ao se investigar os signos referentes às cores em uma perspectiva comparativista, notamos que as línguas divergem significativamente. $\mathrm{Na}$ língua Xavante, da família linguística Jê, “a palavra i udzé parece recobrir tanto a noção de verde, como também amarelo e azul” (BONFIM; QUINTINO, 2013, p. 294). Isto não significa dizer que os indivíduos deste povo sejam incapazes de distinguir o que em português se define como azul, verde e amarelo. Na verdade, no âmbito das convenções adotadas pelos Xavante não deve ter ocorrido, do ponto de vista histórico e funcional da língua até aquele momento, razões suficientes para distinguir estes três trechos do espectro de cores visíveis.

$\mathrm{Na}$ verdade, a história das cores é bem interessante e remonta a alguns milhares de anos. Para isso, basta dar a devida atenção às cores presentes, por exemplo, nas pinturas rupestres (MARSHACK, 1981; BAINES, 1985; CAGE, 1999; SEPÚLVEDA, 2011; entre muitos outros). Foi, no entanto, possivelmente a partir da revolução industrial $(1760$ - 1840) que se deu início à produção 
de diversas cores em larga escala principalmente devido a equipamentos mecânicos. Desde então, a produção de tintas de diversas cores tem se proliferado significativamente. Não há dúvida de que este cenário se põe como novo desafio para os grupos sociais que precisam revisitar suas convenções anteriormente adotadas. Não se deve se surpreender ao ouvir "nude", "marsala", "fúcsia" ou "coral" como cores preferidas de batons ou esmaltes. Nas sociedades em que, por convenção, não há tantas distinções entre cores ou fazer tais distinções seja socialmente irrelevante, é pouco provável que se encontre signos linguísticos para cobrir cada uma dessas frequências de cores. Em Amondawa ${ }^{7}$ (família linguística Tupí-Guaraní), por exemplo, cinco signos parecem ser suficientes para distinguir as cores visíveis, a saber: awy "azul"; pirawy "verde"; iwag "vermelho"; jupim "preto"; e, por fim, itĩg "branco". Nota-se que não há em Amondawa um signo que corresponda, em termos de significado, à cor amarela em português. É possível que parte do espectro correspondente ao amarelo em português se distribua entre o iwag "vermelho" e o pirawy "verde", por exemplo. Pode ser, inclusive, que o significado de awy e azul, pirawy e verde, iwag e vermelho, por exemplo, não sejam biunívocos em Amondawa e em português. As estratégias para se delimitar as tonalidades de cada cor parece terem sido convencionalizadas também de maneiras distintas. Ao passo que em português os adjetivos "claro" e "escuro" contribuem para esta distinção, em Amondawa há o sufixo \{-arawe\}, que indica uma cor aproximada da cor prototípica, podendo variar em tonalidade (claro e escuro, por exemplo). Assim, a partir das cores básicas em Amondawa, derivam-se outras: awyrawe "quaseazul"; pirawyrawe "quase-verde"; iwararawe "rosa (quase-vermelho)"; jupirarawe "cinza (quasepreto)"; e, por fim, itĩrawe "quase-branco".

O que dissemos acima a respeito de palavras também se aplica a qualquer outro termo da língua, inclusive aqueles referentes às entidades gramaticais. $\mathrm{O}$ valor do traço gramatical de gênero feminino em português, por exemplo, não corresponde ao gênero feminino na língua Wari' (família linguística Txapakura). Em português, o gênero gramatical, para além das idiossincrasias, corresponde em parte a flexões que se atribuem às classes de palavras (substantivo e adjetivo, por exemplo) e essencialmente, em termos morfossintáticos, ao processo de concordância com determinantes, quantificadores e adjetivos. Sabe-se, assim, que "caixa" e "armário" são respectivamente substantivos feminino e masculino, pelo fato de lhes acrescentarmos determinantes flexionados, como em "a caixa pesada caiu” e "o armário está sujo". Temos, a partir disso, a distinção, por exemplo, entre “o menino” e “a menina”, “(o) velho” e “(a) velha”, “rápido” e “rápida”. Há ainda nomes que, embora pertençam ao conjunto de seres inanimados, também marcam os gêneros

\footnotetext{
${ }^{7}$ Os dados linguísticos das línguas indígenas Amondawa (Tupí-Guraní) e Aikanã (isolada), que são apresentados neste artigo, foram obtidos por meio da realização do Projeto de Pesquisa "Estudos morfológicos e sintáticos de predicados verbais nas línguas indígenas Amondawa e Aikanã”, sob coordenação do Prof. Dr. Quesler Fagundes Camargos, coautor deste artigo, no âmbito do Programa Institucional de Bolsas de Iniciação Científica (PIBIC/UNIR/CNPq).
} 
gramaticais. É o caso, por exemplo, de "a faca", "a flecha" e "a mesa", que marcam o gênero feminino, e "o garfo", “o arco" e "o armário", que exibem o gênero masculino. De fato, o gênero gramatical em português é intrínseco ao próprio nome e não corresponde necessariamente ao gênero biológico. Na língua Wari' ${ }^{8}$, por sua vez, em termos gramaticais, ao invés de dois, temos na verdade três gêneros gramaticais: feminino, masculino e neutro. Os seres humanos, como arawet "criança", trama" "homem" e narima' "mulher", são marcados morfossintaticamente com os gêneros masculino \{-on\} ou feminino $\{-a m\}$, dependendo do gênero biológico do indivíduo. Os seres animados não humanos e seres inanimados, por sua vez, apresentam um comportamento cindido. Há aqueles, como kopakao "onça" e papak "milho", que recebem a marcação de masculino \{-on\}, e há outros, como miyak "queixada" e pakyn "pedra", que acionam o marcador de gênero neutro \{-ain\}. Dessa maneira, a língua distingue as três sentenças seguintes quanto ao gênero daquilo que foi visto ( $h r i k$ significa "ver" e a lacuna indicada por “__ ” se refere ao que é visto): hrik non __ "eu vi alguém/algo (que pertence à classe de gênero masculino)", hrik nain___ "eu vi algo (que pertence à classe de gênero neutro) e hrik nam __eu vi alguém (que pertence à classe de gênero feminino). Nota-se, portanto, que, em termos contrastivos, além de muitas outras diferenças, a língua Wari’ reserva o gênero feminino $\{-a m\}$ exclusivamente para seres humanos do sexo feminino. Em português, o gênero feminino está presente em nomes cujos referentes são seres animados humanos, não humanos e inanimados.

Deve-se destacar, portanto, que, a partir principalmente dos exemplos apresentados nesta seção, de fato parece que as línguas variam entre si também pelo fato de se fundarem em sistemas de referências distintos, o que fundamenta, por exemplo, a percepção de Saussure (2006) e seus predecessores a respeito da constituição da linguagem humana, o que certamente repercute, conforme será melhor explorado nas próximas seções, na impossibilidade da tradução total enquanto mapeamento bijetivo.

\section{As lógicas de distintos saberes matemáticos não são equivalentes}

Saberes matemáticos originados e situados em diferentes contextos socioculturais baseiam-se em diferentes sistemas lógicos que, necessariamente, não se identificam com o particular sistema lógico eurocêntrico e hegemônico que se estabeleceu a partir da modernidade pela colonialidade. $\mathrm{O}$ modelo de racionalidade que caracteriza a modernidade está baseado em uma matemática cujo

\footnotetext{
${ }^{8}$ Os dados linguísticos da língua indígena Wari’ (família linguística Txapakura) discutidos neste artigo são o resultado de pesquisa descritiva realizada no âmbito do Projeto de Pesquisa "Documentação, descrição e análise das línguas da família linguística Txapakura", sob coordenação do Prof. Dr. Quesler Fagundes Camargos, com financiamento da Fundação de Pesquisa de Rondônia (FAPERO - Chamada Universal no 003/2015) e do Conselho Nacional de Desenvolvimento Científico e Tecnológico (CNPq - Chamada MCTIC/CNPq nº 28/2018).
} 
sistema lógico pressupõe ideias de objetividade, precisão, rigor e universalidade. Devido a tais características, essa matemática assumiu papel de destaque na ciência moderna, fornecendo a ela "não só o instrumento privilegiado de análise, como também a lógica da investigação, e ainda o modelo de representação da própria estrutura da matéria" (SANTOS, 2011, p. 63).

Se não fosse o caráter abissal do pensamento moderno ocidental, que produz "dois lados incomunicáveis, de forma que 'o outro lado da linha' é tido como inexistente, não credível" (SANTOS, 2007b, p. 71), poderia ter sido há muito verificado e reconhecido, com todos os efeitos que isso poderia causar para a superação da ideia de uma epistemologia geral, mudando-se do paradigma da universalidade para o da pluriversalidade (MIGNOLO, 2017), que é falso o aspecto de universalidade atribuído ao sistema lógico eurocêntrico.

Pesquisas etnográficas já produziram significativos exemplos de saberes matemáticos cujas lógicas diferenciam-se da lógica da matemática eurocêntrica. Entre os povos xinguanos Juruna, Kayabi e Suyá, pode-se afirmar que, conforme Ferreira (1994), os conceitos de "mais" e "menos" não correspondem necessariamente aos conceitos convencionalizados na aritmética da matemática eurocêntrica, de modo que a lógica do dar ou ganhar como menos ou mais é substituída pela lógica do princípio da reciprocidade, segundo o qual, o menos da matemática escolar pode significar mais em algumas situações de trocas no contexto cultural destes povos. Vilaça (2019) identifica entre os Wari' um caráter moral e relacional das quantidades, de modo oposto à ideia presente na matemática escolar que concebe um mundo constituído por quantidades objetivas extrínsecas aos sujeitos e suas relações. Ainda entre os Wari', Leite (2012) aponta a variação de significado de termos numéricos de um a dez, de modo que os mesmos termos podem designar quantidades exatas, quando a oralidade está associada à indicação de dedos das mãos, ou quantidades indefinidas, significando muitos. LéviStrauss (2006) cita “derivações aberrantes” na formação de números em algumas línguas indígenas de povos da América do Norte, em cujo sistema aritmético, por exemplo, 7 derivaria de $6+2$. Pica et al. (2004) mostram que, apesar de não existirem no léxico da língua dos Munduruku palavras para números além de 5, eles são capazes de comparar e adicionar grandes números que estão muito além desse intervalo por meio de uma aritmética não exata em um sistema não verbal, distinto do sistema numérico da aritmética escolar. Por sua vez, Suruí e Leite (2013) descrevem a incompletude de significado gerada pela escrita do termo numérico xakalar amakap om "três" na língua do povo Paiter, exemplificando que em culturas de tradição oral, como as de povos indígenas, a escrita da língua pode não ser suficiente para abarcar os contextos significantes dos saberes matemáticos, por não possuir, por exemplo, a complementariedade da linguagem gestual.

No que concerne especificamente a conceitos matemáticos linguisticamente expressos, é-nos interessante identificar o que poderia ser considerado em uma determinada sociedade formas 
geométricas básicas que se originam de lógicas específicas de cada língua. Em Aikanã (língua geneticamente isolada falada no Cone Sul de Rondônia), há um sistema de classificação nominal extremamente rico que dispõe de morfemas que se realizam em nomes, adjetivos e verbos para denotar animacidade, propriedades físicas (líquido, massa, pó), formas físicas (redondo, cilíndrico, longo, curto), por exemplo. Em termos descritivos, nesta língua há sufixos que, ao se realizarem em um predicado verbal transitivo, por exemplo, denotam alguma propriedade do objeto sintático deste verbo. Na sentença hisa dukukapepateẽ, que significa literalmente "eu encostei em algo redondo", o sufixo verbal $\{-p e\}$, em destaque, é o responsável por denotar a forma geométrica esférica da coisa encostada. Ao se dizer hisa dukukatapatee, agora com o sufixo $\{-t a\}$, a coisa encostada tem um formato cilíndrico, como é o caso de uma lata de óleo, por exemplo. Enfim, pode-se afirmar que em Aikanã desenvolveu-se um sistema gramatical sofisticado para classificação nominal, que codifica, além de outras propriedades, formatos geométricos, a partir de uma lógica própria de uma epistemologia desse povo.

Os exemplos discutidos acima nos fornecem pistas a respeito de quais procedimentos metodológicos poderiam ser implementados para identificar, por meio das línguas naturais, o conjunto de convenções adotadas por um determinado grupo para permitir seu exercício da faculdade da linguagem, uma vez que, para Saussure (2006), a língua é um produto social dessa faculdade de linguagem. Por alguma razão, a língua Aikanã desenvolveu um rico sistema de classificação nominal, que codifica inúmeras propriedades, inclusive aquelas que estão contidas no campo semântico da matemática. A existência de sistemas tais como esse revela certa sofisticação que certamente não se encontra em todas as línguas do mundo. De igual modo, há ainda conceitos e convencionalidades em outras línguas que não encontram espaço em Juruna, Kayabi, Suyá, Wari’ e Aikanã. Não se deve se surpreender ao se verificar, por exemplo, a ausência dos conceitos de pirâmide ou losango em determinadas sociedades. Ao passo que tais conceitos possam se mostrar como elementares para alguns povos, não significa que o são para outros.

Tais fatos demonstram que diferenças linguísticas entre povos culturalmente distintos refletem-se em lógicas constituintes de saberes matemáticos não equivalentes, que não coincidem necessariamente com o modelo de racionalidade que caracteriza a modernidade e que se baseia em uma matemática eurocêntrica cujo sistema lógico pressupõe a universalidade.

\section{Há uma impossibilidade de mapeamentos bijetivos entre conjuntos de saberes matemáticos indígenas e eurocêntricos}

Pelo exposto até aqui, considerando que diferentes línguas se baseiam em sistemas de referência distintos e que as lógicas de distintos saberes matemáticos não são equivalentes, é possível 
extrair como consequência destes dois aspectos, que, embora a concepção moderna colonial de matemática pressuponha sua universalidade, e por essa via intenta-se impor um modelo de racionalidade eurocêntrica como efeito da colonialidade, existe na verdade uma impossibilidade de mapeamentos bijetivos entre conjuntos de saberes matemáticos socioculturalmente distintos, como o são os saberes indígenas e eurocêntricos.

Por mapeamento bijetivo pode-se entender a correspondência biunívoca entre elementos de dois conjuntos ou de duas estruturas distintas. Nesse caso, diz-se que as estruturas são isomorfas. Exemplos de mapeamentos bijetivos em matemática são os isomorfismos de grupos e de anéis. Conforme Domingues e Iezzi (2003, p. 161), a ideia por trás do conceito de isomorfismo de grupos em álgebra "é a de separar os grupos em classes disjuntas tais que as propriedades deduzidas para um particular grupo de uma dada classe possam ser transferidas para todos os grupos dessa classe”. No caso de um isomorfismo de anéis, pressupõe-se

uma correspondência biunívoca entre todos os anéis de uma mesma classe [...] de maneira tal que as propriedades pertinentes à estrutura de anel deduzidas para um dos representantes de uma das classes possam ser estendidas para todos os outros anéis da mesma classe, apenas mudando-se convenientemente as notações dos elementos e das operações. Ou, dito de outro modo, que um anel de uma dada classe possa substituir eventualmente, em tudo que diga respeito à estrutura de anel, outro qualquer dessa classe. [...] Reflete bem essa situação imaginar os anéis de uma mesma classe como "cópias" uns dos outros (DOMINGUES; IEZZI, 2003, p. 232).

O conceito de isomorfismo se apresenta também em outras áreas de conhecimento. Por exemplo, em mineralogia, ocorre um isomorfismo entre duas substâncias quimicamente distintas quando elas possuem a mesma estrutura cristalina. Na teoria da administração, há isomorfismo entre duas organizações distintas quanto elas adotam práticas administrativas idênticas em seu campo de atuação. Na Psicologia da Gestalt, haveria um isomorfismo entre os sistemas físicos e o sistema nervoso, isto é, “as Gestalten fenomenológicas da consciência teriam a mesma forma ou seguiriam a mesma matemática topológica que as estruturas físicas" (ENGELMANN, 2002, p. 5).

A partir dessa ideia de isomorfismo, é possível verificar que a concepção moderna de matemática, que intenta atribuir aos saberes matemáticos eurocêntricos um caráter de universalidade, pressupõe a possibilidade de tradução como mapeamento bijetivo entre conjuntos de saberes matemáticos socioculturalmente distintos. Conforme argumentado neste artigo, no entanto, é possível demonstrar a partir dos exemplos de línguas indígenas, que traduções isomórficas de ideias matemáticas são pouco prováveis entre línguas que se baseiam em distintos sistemas de referência, quer seja pela ausência de termos lexicais correspondentes, quer seja pela diferença lógica dos diferentes saberes matemáticos. É inclusive devido a todas estas diferenças entre línguas e culturas 
que alguns autores, em uma perspectiva mais extremista, negam a possibilidade de tradução. A título de exemplo, os adeptos da relatividade linguística, também conhecida como Hipótese de SapirWhorf, pressupõem a impossibilidade de tradução, uma vez que cada língua particular constitui uma visão de mundo singular, de forma que só se é possível acessar por meio desta mesma língua. A respeito desta Hipótese, Crystal (2008, p. 411, tradução nossa) afirma que relatividade é

Um termo usado para identificar uma visão influente da relação entre LÍNGUA e pensamento, geralmente conhecida como relatividade linguística, que afirma, em sua forma mais forte, que a língua determina a maneira como as pessoas percebem e organizam seus mundos. Esta visão (de 'determinismo linguístico') foi exposta pela primeira vez pelo etnólogo alemão Wilhelm von Humboldt (1767-1835): no século XX, veio a ser conhecida como a HIPÓTESE SAPIR-WHORF.

É bem possível que indivíduos de distintos povos possam pensar e interpretar o mundo de modo diferente por causa da língua que falam, uma vez que é por meio dela que se interpreta os fatos do mundo (cf. WHORF, 1956). O contrário também poderia ser dito. Em certa medida, as línguas variam possivelmente para atender à maneira como um determinado povo pensa e interpreta o mundo. No entanto, há ainda inúmeros outros conjuntos de fatos linguísticos que aproximam todas essas línguas, de tal forma que é possível não só a comunicação como também a tradução.

No campo da literatura, há muitas vozes contrárias a possíveis traduções de textos poéticos, por exemplo. Utilizando-se de estratégias metafóricas, o filósofo Voltaire (1694 - 1778) ilustra bem essa concepção: "Perdoai a cópia em favor do original e lembrai-vos, sempre, quando virdes uma tradução, que vedes uma fraca estampa de um belo quadro" (VOLTAIRE, 1973, p. 40). Jakobson (1971, p. 72) também afirmou que “a poesia, por definição, é intraduzível”. Apesar disso, a tradução, pelo visto, existe desde o momento em que o ser humano se viu na necessidade de se comunicar com indivíduos falantes de outras línguas. Não só isso, mas também não faltam trabalhos que proponham metodologias de tradução, como é o caso de Haroldo de Campos, que explora, de forma análoga, recursos articulados na língua de partida (principalmente no que diz respeito à forma) para reproduzilos na língua de destino, o que designou como transcriação.

De todo modo, deve-se destacar que, de fato, não deve existir tradução absoluta ou total, uma vez que essa possibilidade se torna inatingível à medida em que o próprio ato de comunicar, mesmo intralinguisticamente, também não é absoluto. Esta imprecisão talvez esteja fundada na própria natureza da linguagem humana. Durante o ato da comunicação, não seria a língua, em seu sentido mais intrínseco, já uma tradução de pensamentos e fatos do mundo real? Para Sapir e Whorf, a língua traduz o mundo e a realidade. Assim, se neste nível de tradução já há imprecisão, parcialidade e limitação, mais ainda haverá quando o ato de traduzir envolver duas línguas. 
Em outra perspectiva, pode-se citar Jakobson (2001), que, ao conceber em termos tipológicos três tipos de tradução, a saber: intralingual ou reformulação, interlingual ou tradução propriamente dita e, por fim, tradução intersemiótica ou transmutação, afirmou que

o significado de um signo lingüístico não é mais que sua tradução por um outro signo que the pode ser substituído, especialmente um signo "no qual ele se ache desenvolvido de modo mais completo", como insistentemente afirmou Peirce, o mais profundo investigador da essência dos signos (JAKOBSON, 2001, p. 64).

Diante dessas considerações, a tradução é sim possível à medida em que se compreende a língua como um sistema de comunicação. Se não fosse verdade, não seria possível a comunicação entre falantes de línguas distantes, o que é viabilizado por meio da tradução. Por óbvio, a correspondência não é sempre exata entre as línguas. Retornando à Saussure (2006), dificilmente encontraremos um conjunto considerável de signos em línguas distintas que apresentam uma correspondência exata de significação. Este fato, no entanto, não impossibilita o trabalho de tradução, uma vez que, conforme Jakobson (2001, p. 66), "toda experiência cognitiva pode ser traduzida e classificada em qualquer língua existente. Onde houver uma deficiência, a terminologia poderá ser modificada por empréstimos, calços, neologismos, transferências semânticas e, finalmente, por circunlóquios". É devido a isso, por exemplo, que, após o contato com a sociedade não indígena, o povo Guajajára (falante de uma língua da família linguística Tupí-Guaraní) passou a utilizar a expressão karaiw àkàgwer, que literalmente significa "a ex-cabeça (caveira) do não indígena" para se referir ao aparelho de rádio, possivelmente porque os equipamentos eletrônicos mais antigos tinham um formato semelhante à "caveira" e "falavam" na língua do não indígena.

Em outra perspectiva, tendo em vista a impossibilidade de tradução isomórfica por mapeamento bijetivo, em que haja uma correspondência de um para um entre as línguas, pode-se conceber a tradução como um processo fundamentalmente criativo de produção de significados. A "tradução" formulada nestes termos é bem explorada em Catford (1965, p. 48, tradução nossa), segundo o qual

[...] deve ficar claro que um tipo restrito de "transferência de significado" de uma língua para outra é possível; mas é igualmente claro que isso não é o que normalmente se entende por "tradução". Na tradução, há substituição de significados da língua-fonte por significados da língua-meta: sem transferência de significados da língua-meta para a língua-fonte. Na transferência, há uma implantação de significados da língua-meta no texto da língua-fonte. Esses dois processos devem ser claramente diferenciados em qualquer teoria da tradução.

Portanto, para Catford (1965, p. 20, tradução nossa), em uma teoria da tradução, não se espera necessariamente um processo de "transferência" de significados - embora possa ocorrer, mas sim "a 
substituição de material textual em um idioma (língua-fonte) por material textual equivalente em outro idioma (língua-meta)”. Neste sentido, o tradutor terá como tarefa, em um primeiro momento, interpretar adequadamente o texto da língua de origem e, a partir de sua compreensão, produzir um novo texto na língua de destino, de modo que o resultado final compreenda um material textual equivalente na primeira língua. Pode ser que, em alguns contextos, a equivalência entre os textos nas duas línguas seja em maior ou menor grau, a depender obviamente de vários fatores linguísticos e não linguísticos. É possivelmente neste ponto em que Haroldo de Campos reivindica o papel autoral do tradutor. Amaral (2013, p. 265-266) também assim compreende quando afirma que

Para Haroldo de Campos, só é possível a tradução com a recriação, daí a opção pelo vocábulo transcriação. Ao recriar, o tradutor se investe na função de autor e, embora tenha em mãos uma partitura e a ela deva ser fiel, interpreta-a como um novo criador, em pleno exercício de seus instrumentos sincrônicos. Autor e transcriador estão irmanados pelo viés sincrônico de uma mesma luz estética.

Pesquisas produzidas por estudantes indígenas de um curso de licenciatura intercultural na Amazônia ilustram casos de traduções não isomórficas de ideias matemáticas e a impossibilidade de tradução via mapeamento bijetivo. Por exemplo, Cacami Cao Orowaje, em seu trabalho de conclusão de curso, relata:

Durante minha pesquisa para construção do TCC percebi que existem vários conceito e nome da matemática escolar em língua portuguesa que não tem um igual na língua e na cultura do meu povo. Por exemplo, o termo "pirâmide" e o seu conceito é ensinado na matemática escolar no conteúdo de geometria espacial, mas não identifiquei na língua do meu povo um termo equivalente ou mesmo a ideia de um objeto geométrico semelhante ou parecido com pirâmide. Esse é um exemplo de desafio para o ensino bilíngue de matemática na escola indígena. O que é necessário fazer quando os nomes não têm um igual na cultura e na língua de cada povo? Os conceitos que eu não consegui identificar os nomes na língua materna, eu vou convidar os mais velhos junto com comunidade para nós discutir junto para criar o nome para cada uma delas, depois que nós criarmos os nomes para cada uma delas, elas vão entrar no conteúdo da escola para trabalhar de forma bilíngue com os alunos. Isso não vai ser difícil de criar porque nós já criamos vários nomes para outros objetos que não existiam na cultura do povo. Por exemplo, sapato (kayikatim), calça (mao mao at). O nome não vai ser o mesmo, mas vai ter o mesmo significado. Esses conceitos que eu não encontrei na língua materna, os meninos já sabem o nome na língua portuguesa porque eles estão aprendendo na escola (OROWAJE, 2015, p. 29).

Por sua vez, em seu trabalho de conclusão de curso de graduação, o pesquisador indígena Adriano Pawah Suruí também faz o seguinte relato:

Ao longo da coleta de dados para construção do meu TCC, deu para perceber que existem vários conceitos da matemática escolar que podem não ter equivalentes na 
língua e na matemática tradicional do povo Paiter. Essa informação foi encontrada, de acordo com as falas das pessoas mais sábias ou experientes na língua Paiter da comunidade. E ainda assim, elas não têm uma definição certa na língua e na cultura do povo paiter; até porque no conhecimento Paiter não se dava para perceber que existiam as geometrias sólidas. Para tanto, alguns nomes foram encontrados de acordo com a realidade e os conhecimentos que pessoas mais velhas têm em si. Por exemplo, os termos esfera (Penẽm-ah), cilindro (makor ahp) e cone (Ibog̃ahp apeh), essa nomenclatura foi dada de acordo com os conhecimentos que os mais velhos tem pelos objetos idênticos parecidos com os mesmos. O termo Penẽm-ah quer dizer "objeto que rola sem direção". Já o termo makor ahp quer dizer "parte do tronco de bambu", que é parecido com um cilindro. O termo Ibog̃ahp apeh quer dizer "espinho da árvore maracatiara", que é parecido com o cone. Outros termos da geometria espacial não foram identificados na sua forma definida em Paiter, tais como os termos pirâmide, cubo e paralelepípedo. Não existem esses conceitos na língua Paiter. Assim como também existem conceitos e ideias próprias da matemática do povo Paiter que não tem um equivalente na matemática escolar, principalmente quando o significado dos termos, conceitos e palavras estão relacionados ao contexto. Portanto, alguns conteúdos existentes na matemática escolar não existem na matemática tradicional do povo Paiter Surui e vice-versa. Nesse caso, tem-se um desafio nas escolas Paiter referente ao ensino bilíngue de matemática (SURUÍ, 2015, p. 46).

Deve-se destacar o interessante processo que levou Surui (2015) a propor as expressões penẽm-ah, makor ahp e ibog̃ahp apeh para referir-se, respectivamente, aos conceitos de esfera, cilindro e cone da geometria espacial da matemática eurocêntrica. Isto porque o conceito de curvilinearidade dos Paiter, que encontra fundamentos nessa geometria espacial, parece estar em termos linguísticos gramaticalizado na língua, o que significa dizer que este não é apenas um item listado no vocabulário como ocorre na língua portuguesa, mas está presente na gramática da língua. Cabral et al. (2014, p. 166) afirmam que os nomes em Paiter subdividem-se em duas classes nominais. Há os nomes que "são percebidos ou considerados como redondos, circulares, curvilíneos, esféricos ou circunscritos”. Nestes deve emergir o enclítico $a h$, cuja função gramatical é indicar esta forma física, conforme os seguintes exemplos: gor ah pep ah "intestino grosso"; walet nom ah "seio (mulher)"; gonio ah "umbigo"; ikahp beti ah "dentes molares"; ikahp sak ah "dentes do siso"; gopam ah "porakê"; nambe ah "tucunaré"; bokop ah "banana"; akop ah "cacau" (CABRAL et al., 2014, p. 167-168); entre muitos outros. Nota-se que a expressão penẽm-ah, que foi criada para designar o conceito de esfera, exibe este mesmo enclítico $a h$. De fato, tal concepção está presente na interpretação que Suruí (2015, p. 46) atribui ao neologismo: “objeto que rola sem direção”. Todos estes signos, por sua vez, diferenciam-se daqueles em que o enclítico ah não se manifesta, uma vez que correspondem a referentes que "não são concebidos como detentores dessas propriedades" (CABRAL et al., 2014, p. 166).

Merece destaque ainda as outras duas expressões, makor ahp e ibogahp apeh, utilizadas por Suruí (2015) para designar o "cilindro" e o "cone”. Deve-se destacar que estas duas expressões já 
pertencem ao léxico Paiter para se referir, respectivamente, a (i) um pedaço de bambu cortado de forma que seja possível utilizá-lo como instrumento para beber chicha (bebida tradicional) e (ii) o espinho da árvore maracatiara. Retomando o conceito de signo de Saussure (2006), o qual é formado pelo significante e pelo significado, nota-se que Suruí (2015), a partir de significantes já existentes em Paiter, atribuiu-lhes os significados de cilindro e cone definidos conforme conceitos da geometria espacial da matemática eurocêntrica, o que ilustra a possibilidade de colonialidade do saber em traduções de ideias matemáticas entre línguas distintas, prevalecendo ao final o saber da matemática eurocêntrica. Em termos tipológicos, poderíamos classificar o processo aqui apresentado como neologismo semântico (cf. BOULANGER, 1979), uma vez que Suruí (2015) amplia a significação (nos termos de Saussure, 2006) de makor ahp e ibog̃ahp apeh. É certo que esta ampliação não foi aleatória, mas seguiu princípios metafóricos e icônicos, à medida em que o formato cilíndrico do instrumento para tomar chicha e o formato cônico do espinho da maracatiara foram relevantes para se estabelecer esta relação metafórica.

Estes resultados de pesquisas em etnomatemática realizadas por estudantes indígenas de povos de Rondônia, além de representarem a importante manifestação de vozes de povos subalternizados pelo colonialismo a respeito de seus próprios conhecimentos e línguas, ilustram como as diferenças entre saberes matemáticos, que estão baseados em línguas com diferentes sistemas de referência, oportunizam a problematização da concepção de tradução que pressupõe o mapeamento bijetivo entre saberes e línguas distintas e está associada à ideia de universalidade da matemática eurocêntrica.

A partir de tal problematização, é possível repensar a ideia de bilinguismo no ensino de matemática em escolas indígenas, na busca de se superar aspectos de colonialidade do saber que ainda se fazem presentes nesse espaço. Assim, o tipo de bilinguismo no ensino de matemática que vise a decolonialidade dos saberes indígenas na escola necessariamente precisa se desvincular de concepções modernas de saberes matemáticos e de tradução total que, sob o pretexto de valorização dos saberes locais, podem oportunizar, isto sim, a tradução de tais saberes em termos dos próprios saberes e do pensamento ocidental. Nesse sentido, pode-se reproduzir a colonialidade do saber, na medida em que "há um legado epistemológico do eurocentrismo que nos impede de compreender o mundo a partir do próprio mundo em que vivemos e das epistemes que lhes são próprias" (LANDER, 2005, p. 3).

O caso da tradução de "cone" e "cilindro" como "espinho de maracatiara" e "instrumento para beber chicha", na referida pesquisa de Suruí (2015), ilustra esse risco da colonialidade do saber à medida em que, localmente, não haveria um propósito, por exemplo, para o cálculo de área superficial ou de volume do espinho de uma árvore ou de um copo de chicha entre os Paiter. Assim, os termos 
"cone" e "cilindro" do léxico do português encerram um conjunto de ideias e conceitos da matemática eurocêntrica que podem não possuir equivalentes biunívocos em Paiter. Nesse caso, na ausência de uma biunivocidade de significados entre as línguas, cujos sistemas de referência são distintos, a tradução que se quer isomórfica impõe ao conceito de "espinho de maracatiara" e "instrumento para beber chicha" da cultura Paiter os significados da geometria espacial da matemática eurocêntrica, constituindo-se um típico exemplo de colonialidade do saber que, se não devidamente problematizada, poderia vir a ser reproduzida no âmbito escolar.

Por óbvio, no âmbito da educação escolar indígena, não se pode negar aos Paiter o conhecimento, por exemplo, da matemática eurocêntrica, se esta for sua escolha, e tampouco se pode institucionalizar um sistema de ensino em que, de forma deliberada, suplanta a episteme dos Paiter pela episteme eurocêntrica do conhecimento matemático. Ademais, extraem-se também desta discussão algumas implicações para pesquisas em etnomatemática em contextos escolares indígenas que, ao aventarem a possibilidade de se ensinar a matemática já institucionalizada no currículo a partir dos saberes locais como início, mas com a matemática eurocêntrica como fim, ou pela tradução de conceitos entre português e línguas indígenas, mesmo que de forma não intencional, podem estar contribuindo para a promoção de paradigmas da modernidade, incluindo-se o universalismo eurocêntrico excludente, oposto a uma pluriversalidade epistêmica.

\section{Considerações finais}

Esse artigo teve por objetivo problematizar a ideia de tradução de saberes matemáticos em contextos da educação escolar indígena, considerando que diferentes línguas se baseiam em sistemas de referência distintos, que as lógicas de diferentes saberes matemáticos não são equivalentes e que, portanto, há uma impossibilidade de mapeamentos bijetivos entre conjuntos de saberes matemáticos indígenas e eurocêntricos.

Verificou-se que a ideia de tradução isomórfica de saberes matemáticos em contextos indígenas se aproxima de uma concepção de linguagem e de matemática característica da modernidade, de modo que a tradução de saberes matemáticos no âmbito da educação escolar indígena precisa ser problematizada, com vistas à superação de perspectivas colonialistas que, sob o aspecto de certos tipos de bilinguismo, pode ainda promover a imposição sociocultural da matemática eurocêntrica em detrimento dos saberes locais, promovendo a colonialidade do saber.

Em outros termos, se não problematizada, a prática de certos tipos de tradução de saberes matemáticos em contextos indígenas pode transformar os próprios professores indígenas em reprodutores da colonialidade do saber nas escolas de suas comunidades, principalmente quando se intenta traduzir o saber matemático local em termos da matemática eurocêntrica, baseando-se na ideia 
de mapeamentos bijetivos e traduções isomórficas, ou quando se propõem a "contextualização" da matemática eurocêntrica nas realidades locais, ou ainda quando se propõe partir dos saberes matemáticos locais para se "compreender" os saberes da matemática eurocêntrica.

A partir do exposto no artigo, propõe-se pensar os saberes matemáticos indígenas a partir de suas próprias lógicas e a partir dos sistemas de referência próprios de cada língua, de modo que a tradução entre os saberes locais e ocidentais se dê por outras perspectivas que não seja a do mapeamento bijetivo. Assim, diante dos riscos de uma tentativa de tradução total e isomórfica, a tradução pode ser concebida como um processo fundamentalmente criativo de produção de significados, em que haja entre as versões nas duas línguas certa equivalência, sem que ocorra obviamente qualquer processo de transferência de significados. Como bem destacado por Mignolo (2004), não se trata de uma defesa ou celebração dos saberes não ocidentais em detrimento dos saberes ocidentais, mas de se realizar a necessária crítica ao caráter hegemônico do pensamento ocidental.

\section{Referências}

AMARAL, B. H. R. A. Haroldo de Campos e a tradução como prática isomórfica: as transcriações. Revista Eutomia, Recife, v. 11, n. 1, p. 261-268, jan./jun. 2013.

BAINES, J. Color terminology and color classification: ancient Egyptian color terminology and polychromy. American Anthropologist, v. 87, 282-297, 1985.

BONFIM, E. S.; QUINTINO, W. B. I'wamnari: as cores e a cosmologia xavante. Revista FSA, Teresina, v. 10, n. 4, art. 15, p. 290-303, out./dez. 2013.

BOULANGER, J. C. Problématique d'une métholodologie dynamique d'identification des neólogismes en terminologie. In: GUILBERT, Louis. Néologie et lexicologie. Paris: Larousse, 1979. p. 36-46.

CABRAL, A. S. A. C; KALAPALO, K.; AWETÍ, M. M.; OLIVEIRA, S. C. S.; SURUÍ, U. Classificadores nominais em três línguas indígenas da Amazônia brasileira: ampliando tipologias. Revista Brasileira de Linguística Antropológica, Brasília, v. 6, n. 1, jul. 2014.

CAGE, John. All What Meaning had Colour in Early Societies? Cambridge Archaeological Journal, v. 9, n. 1, p. 109-126,1999.

CATFORD, J. C. A Linguistic Theory of Translation: an essay in Applied Linguistcs. Oxford: Oxford University Press, 1965.

CRYSTAL, D. A dictionary of Linguistics and Phonetics. 6th ed. Malden, MA: Blackwell Publishing, 2008.

D’AMBROSIO, U. Etnomatemática: arte ou técnica de explicar e conhecer. São Paulo: Ática, 1990. 
D’AMBROSIO, U. Etnomatemática: elo entre as tradições e a modernidade. Belo Horizonte: Autêntica, 2001.

DESCARTES, R. Discurso do Método. Tradução de Ciro Mioranza. São Paulo: Escala, 2003.

DESCARTES, R. Discurso do método. Tradução de Paulo Neves. Porto Alegre: L\&PM, 2008.

DOMINGUES, H. H.; IEZZI, G. Álgebra moderna. São Paulo: Atual, 2003.

ENGELMANN, A. A psicologia da gestalt e a ciência empírica contemporânea. Psicologia: Teoria e Pesquisa, Brasília, v. 18, n. 1, p. 1-16, abr. 2002.

FANTINATO, M. C.; FREITAS, A. V. (org.). Etnomatemática: concepções, dinâmicas e desafios. Jundiaí: Paco Editorial, 2018.

FERREIRA, M. K. L. Com quantos paus se faz uma canoa! A matemática na vida cotidiana e na experiência escolar indígena. Brasília: MEC, 1994.

FEYERABEND, P. Contra o método. São Paulo: Editora Unesp, 2011.

HOBBES, T. Leviatã. Coleção Os Pensadores. São Paulo: Nova Cultural, 1996.

JAKOBSON, R. Lingüística e comunicação. Tradução de Izidoro Blikstein e José Paulo Paes. São Paulo: Cultrix, 2001.

JOSEPH, G. G. Foundations of eurocentrism in mathematics. Race \& Class, v. 28, n. 3, p. 13-28, 1987.

KNIJNIK, G. Ethnomathematics and political struggles. Zentralblatt für Didaktik der Mathematik, v. 30, n. 6, p. 188-194, 1998.

LANDER, E. (org.). A colonialidade do saber: eurocentrismo e ciências sociais. Perspectivas latinoamericanas. Buenos Aires: CLACSO, 2005.

LEITE, K. G. Notas sobre a etnomatemática Wari. In: CONGRESSO BRASILEIRO DE ETNOMATEMÁTICA, 4., 2012, Belém. Anais [...]. Belém: IEMCI/UFPA, 2012. p. 1-10. Disponível em: http://www.cbem4.ufpa.br/anais/Arquivos/CC_LEITE.pdf. Acesso em: 14 jul. 2020.

LÉVI-STRAUSS, C. A origem dos modos à mesa. São Paulo: Cosac Naify, 2006.

MARSHACK, A. On Paleolithic Ochre and the Early Uses of Color and Symbol. Current Anthropology, v. 22, n. 2, p. 188- 191, 1981.

MIARKA, R. Etnomatemática: do ôntico ao ontológico. 2011. 427 f. Tese (Doutorado em Educação Matemática) - Universidade Estadual Paulista, Instituto de Geociências e Ciências Exatas, Rio Claro, 2011.

MIGNOLO, W. D. Colonialidade: o lado mais escuro da modernidade. Revista Brasileira de Ciências Sociais, São Paulo, v. 32, n. 94, p. 1-18, 2017.

MIGNOLO, W. Os esplendores e as misérias da "ciência": colonialidade, geopolítica do conhecimento e pluri-versalidade epistémica. In: SANTOS, B. S. (org.). Conhecimento prudente 
para uma vida decente: um discurso sobre as ciências revisitado. São Paulo: Cortez, 2004. p. 667709.

MILLROY, W. L. An Ethnographic study of the mathematical ideas of a group of Carpenters. Virginia: National Council of Teachers of Mathematics, 1992. (Journal for Research in Mathematics Education Monograph, 5)

MONTEIRO, H. S. R. O ensino de matemática na educação escolar indígena: (im)possibilidades de tradução. 2016. 172 f. Tese (Doutorado em Ensino de Ciências e Matemática) - Instituto de Física, Universidade Estadual de Campinas, Campinas, SP, 2016.

MOREIRA, V. C. Leibniz e a linguagem. Rio de Janeiro: Jorge Zahar, 2005.

NOBRE, D. De que bilinguismo falamos na formação de professores? In: SIMPÓSIO INTERNACIONAL DE ENSINO DA LÍNGUA PORTUGUESA, 2., 2012, Uberlândia. Anais [...]. Uberlândia: EDUFU, 2012. p. 1-8. Disponível em: http://www.ileel.ufu.br/anaisdosielp/wpcontent/uploads/2014/06/volume_2_artigo_096.pdf. Acesso em: 7 jul. 2020.

OROWAJE, W. C. C. Saberes matemáticos do povo Cao Orowaje. 2015. 30 f. Trabalho de Conclusão de Curso (Licenciatura em Educação Básica Intercultural) - Departamento de Educação Intercultural, Universidade Federal de Rondônia, Ji-Paraná, 2015.

PICA, P.; LEMER, C.; IZARD, V.; DEHAENE, S. Exact and approximate arithmetic in an amazonian indigene group. Science, v. 306, p. 499-503, 2004.

POWELL, A. B.; FRANKENSTEIN, M. Ethnomathematics: Challenging eurocentrism in mathematics education. Albany: State University of New York, 1997.

QUIJANO, A. Colonialidade do poder e classificação social. In: SANTOS, B. S.; MENESES, M. P. (org.). Epistemologias do Sul. São Paulo: Cortez, 2010.

QUIJANO, A. Colonialidade do poder, eurocentrismo e América Latina. In: LANDER, E. (org.). A colonialidade do saber: eurocentrismo e ciências sociais. Perspectivas latino-americanas. Buenos Aires: CLACSO, 2005. p. 117-142.

ROSA, M.; OREY, D. C. Etnomodelagem: a arte de traduzir práticas matemáticas locais. São Paulo: Livraria da Física, 2017.

SANTOS, B. S. A crítica da razão indolente: contra o desperdício da experiência. São Paulo: Cortez, 2011.

SANTOS, B. S. Para além do pensamento abissal. Novos Estudos, v. 79, p. 71-94, 2007b.

SANTOS, B. S. Reinventar a teoria crítica e reinventar a emancipação social. São Paulo: Boitempo, 2007a.

SANTOS, B. S. Um discurso sobre as ciências. São Paulo: Cortez, 2010.

SAUSSURE, F. Curso de linguística geral. Tradução de A. Chelini, J. P. Paes e I. Blikstein. 27. ed. São Paulo: Cultrix, 2006.

SEPÚLVEDA, Marcela. Pinturas rupestres y tecnología del color en el extremo sur de Chile.

Magallania, v. 39, n. 1, p. 193-210, 2011. 
SURUÍ, A. P. Saberes matemáticos do povo Paiter Suruí. 2015. 48 f. Trabalho de Conclusão de Curso (Licenciatura em Educação Básica Intercultural) - Departamento de Educação Intercultural, Universidade Federal de Rondônia, Ji-Paraná, 2015.

SURUÍ, U. A.; LEITE, K. G. Incompletude de significado na grafia do termo numérico xakalar amakap om da língua Paiter. In: ENCONTRO INTERNACIONAL SOBRE LÍNGUAS E CULTURAS DOS POVOS TUPÍ, 4., 2013, Ji-Paraná. Anais [...]. Ji-Paraná: DEINTERUNIR/LALI-UnB, 2013.

SWARTZ, E. Emancipatory narratives: rewriting the master script in the school curriculum. Journal of Negro Education, v. 61, n. 3, p. 341-355, 1992.

VILAÇA, A. Inventing nature Christianity and science in indigenous Amazonia. HAU: Journal of Ethnographic Theory, v. 9, n. 1, p. 44-57, 2019.

VOLTAIRE, F. A. Cartas Inglesas. Traduzido por Marilena de Souza Chauí Berlinck. São Paulo: Editora Abril Cultural, 1973. (Coleção Os Pensadores, 23).

WHORF, B. Language, Thought and Reality: selected writings. Cambridge: Technology Press of Massachusetts Institute of Technology, 1956.

WILLINSKY, J. Learning to divide the world: Education at empire's end. Minneapolis: University of Minnesota Press, 1998.

a 